\title{
Antibiotics prescription practices for provisional malaria cases in three hospitals in Moshi, northern Tanzania
}

\author{
JAFFU CHILONGOLA ${ }^{1,2^{*}}$, ELIZABETH MSOKA ${ }^{2}$, ADINAN JUMA ${ }^{3}$, DEBORA C. KAJEGUKA ${ }^{1}$, HADIJA SEMVUA ${ }^{2,3}$, \\ ELIMSAADA KITUMA ${ }^{1}$, EDITH KWIGIZILE ${ }^{4}$ and BALTHAZAR NYOMBI ${ }^{2,3}$ \\ ${ }^{1}$ Kilimanjaro Christian Medical University College, P.O. Box 2240, Moshi Tanzania \\ ${ }^{2}$ Kilimanjaro Clinical Research Institute, P.O. Box 2236, Moshi Tanzania \\ ${ }^{3}$ Kilimanjaro Christian Medical Centre, P.O. Box 3010, Moshi Tanzania \\ ${ }^{4}$ Stefano Moshi Memorial University College, P.O Box 881, Moshi Tanzania
}

\begin{abstract}
Background: Irrational antibiotic use is an important factor for development and spread of resistance to currently used antibiotics. This study was carried out to assess antibiotic prescribing practices among cases diagnosed as malaria at three hospitals in Moshi Municipality in northern Tanzania.

Methods: This was a cross sectional, retrospective study that included patients files from Kilimanjaro Christian Medical Centre (KCMC), Mawenzi Regional Hospital and St Joseph Hospital. Patient files whose primary provisional diagnosis was malaria were analysed using a convenient sampling method. Variables of interest were the types of medications prescribed, whether or not a laboratory test was requested and treatment was initiated before laboratory reports.

Results: A total of 250 patients' files were included in the analysis (KCMC=62.8\%; Mawenzi=23.2\%; St. Joseph=14.0\%). In 232 (92.8\%) prescriptions made in the three hospitals, laboratory tests were requested to confirm diagnoses. Among laboratory tests requested, $89.2 \%$ were blood slides for microscopic detection of malaria parasites, $3.01 \%$ malaria rapid diagnostic tests and 3.01\% other tests. The majority of prescriptions across all three hospitals (KCMC $=86.4 \%$; Mawenzi=91.4\%; St. Joseph=72.4\%; $\left.X^{2}=7.787\right)$. Clinicians at Mawenzi were more likely to start treatment before laboratory findings than their counterparts at KCMC and St Joseph hospitals $\left(X^{2}=7.787, p \leq 0.05\right)$. A significantly higher number of prescriptions made before laboratory findings were observed at KCMC than Mawenzi and St. Joseph hospitals $\left(X^{2}=7.787, p<0.05\right)$. Prescriptions from KCMC were more likely to include at least one type of antibiotic than in the other two facilities. Over one third (KCMC=34.0\%; St. Joseph=42.1\%; Mawenzi=38.1\%) of the prescriptions made contained at least one type of an antibiotic. There was a strong association between health facilities and antibiotics prescription in which KCMC prescribed antibiotics at the highest rate while Mawenzi Regional Hospital prescribed antibiotics at the lowest rates $\left(X^{2}=29.234, p<0.001\right)$.

Conclusion: Antibiotics are prescribed at a high rate among provisionally diagnosed malaria cases before availability of laboratory results. Efforts should be made to improve laboratory services in terms of trained personnel and equipment to reduce irrational use of antibiotics in provisionally diagnosed malaria cases.
\end{abstract}

Keywords: malaria, antibiotics, prescription, diagnosis, resistance, Tanzania

\section{Introduction}

Antimicrobial agents, including antibiotics are the most common group of drugs prescribed in hospitals worldwide (Calva, 1996; Straand et al., 1998). However, misuse of antibiotics is a worldwide phenomenon (Mnyika \& Killewo, 1991; Biswas et al., 2000), with emergence of serious infections caused by multi-level antibiotic-resistant bacteria (Calva, 1996; Straand et al., 1998; Mshana et al., 2013). Infections caused by multi-drug resistant bacteria are associated with higher incidences of mortality and prolonged hospital stay (Davey et al., 2013). While it is a common phenomenon for patients to request antibiotics (Pechere, 2001), it is more common for physicians to prescribe antibiotics for non-bacterial febrile infections (Straand et al., 1998). Reported factors associated with the development of antibiotic resistance include nonadherence, under dosing, counterfeit products and irrational use of the drugs in human and veterinary medicine (Prescott \& Baggot, 1993; Okeke et al., 1999; van den Bogaard \& Stobberingh, 2000; Singer et al., 2003; Turnidge, 2004; Phillips et al., 2004).

\footnotetext{
* Correspondence E-mail: jchilongola@kcri.ac.tz
} 
Furthermore, previous reports from India indicate that up to $80 \%$ of in-patients, regardless of the type of disease they had, were given an antibiotic (Sharma et al. 2012) and a high proportion of patients in other countries were prescribed an antibiotic irrespective of the established diagnosis (Gilson et al., 1993; Reyburn et al., 2007; Awad et al., 2007; Karande et al., 2005; Bharathiraja et al., 2005; Kumar et al., 2008). Irrational use of antibiotics based on presumptive, clinical diagnosis alone or on misdiagnosis due to poor technical expertise on reading and interpretation of results have a significant contribution to the rapid spread of antibiotic resistance (Fabricant \& Hirschhorn, 1987; Straand et al., 1998; Biswas et al., 2000; Siddiqi et al., 2002; Buke et al., 2005; Kardas et al., 2005).

In developing countries, the use of treatment guidelines based on clinical presentations is common due to congestion of patients in health care facilities accompanied with a small number of prescribers and the lack of reliable laboratory capacities (Chandler et al., 2008; Van den Broek et al., 2014; Ngasala et al., 2008; Petti et al., 2006). In Tanzania, although the National Standard Treatment Guidelines and The National Essential Medicines List are available at healthcare facilities (Massambu \& Mwangi, 2009), strict adherence to these guidelines is a critical challenge that needs to be addressed. In a survey among 25 European countries, statistics indicate that antibiotic usage in health facilities is increasing and that over one third of prescriptions are not compliant with evidence-based guidelines (Zarb et al., 2011).

The worldwide increase in the rate of antimicrobial drugs resistance calls for more efforts to identify specific causes and practices that aggravate the problem. Whether such factors are professional, infrastructural, social or personal it remains to be explored. The prescribing behaviour of clinicians plays a key role in the consumption of antibiotics and is a potential tool for control and containment of antimicrobial resistance. The present study was carried out to assess the extent of antibiotic prescription and practices in an attempt to understand the magnitude of the problem before strategies to control it can be put in place.

\section{Materials and Methods}

\section{Study site and design}

This retrospective descriptive hospital based study involved three hospitals located in Moshi Municipality in northern Tanzanian. They included Kilimanjaro Christian Medical Centre (KCMC), Mawenzi Regional Hospital and St. Joseph Hospital. KCMC is an Institution of the Good Samaritan Foundation of Tanzania. It has a 500-bed capacity and the second largest consultant referral teaching hospital in the country serving patients from northern and central regions of Tanzania. KCMC comprises a Medical University College which offers undergraduate and post-graduate training. It has a relatively well equipped Clinical laboratory for patient care with a back-up advanced biotechnology laboratory. Mawenzi is a government owned hospital with a 300 bedcapacity and serves mainly the community of Kilimanjaro Region. St Joseph Hospital is a Catholic Church owned and designated District Hospital for Moshi Municipality with a 100-bed capacity. The three facilities which are the largest health facilities in Moshi were selected for convenience to represent both private and public health care delivery in the Municipality.

\section{Sampling Methods}

Convenient sampling method was used to select patients' files from the medical records departments in all three hospitals whereby all patient files with malaria as the primary diagnosis were included. Sample size was calculated using Epi Info computer software using the Stat Calc calculator for cross-sectional studies with the expected proportion of irrational antibiotic prescription of 0.5 for unknown rates (Nsimba, 2006). Selection of files was done until the desired number of files for each site was reached. A total of 150 files, 50 files and 50 files were studied in KCMC, Mawenzi Regional Hospital and St Joseph hospitals, respectively. The lead investigator reviewed all patients' files to ascertain if they met all the necessary criteria to be 
included in the analyses. The total duration for collection of data from the three study centres was six months, two months in each centre.

\section{Data analysis}

Data were collected using an abstraction form by a team of investigators at the medical record departments. Information captured included diagnosis, type of antibiotics given, other types of drugs prescribed, type of laboratory test requested and if treatment was started before or after laboratory results. Study investigators determined whether the antimicrobial regimen in each patient's file was necessary or unnecessary. Data used in the present study were strictly from patients' files whose primary provisional diagnoses were malaria, and without any other recorded bacterial disease. Data analysis was done by using STATA software v12. Mainly, data was analysed for descriptive statistics and logistic regressions for associations.

\section{Ethical considerations}

Ethical clearance was obtained from the Kilimanjaro Christian Medical University College Ethics Committee. Permission to conduct the study was obtained from the Executive Director of KCMC as well as hospital directors of Mawenzi Regional Hospital and St Joseph Hospital. Each patient's file was given a study identification number and confidentiality was maintained. No names or any personal information was recorded from the patient files.

\section{Results}

A total of 250 patients' files were retrieved for inclusion in the present study out of which 157 (62.8\%), 58 (23.2\%) and 35 (14.0\%) files were from KCMC, St. Joseph and Mawenzi, respectively. Antibiotic prescriptions among patients who had provisional diagnosis of malaria were mostly made by Residents at KCMC and Intern at Mawenzi (Table 1). In 232 (92.8\%) prescriptions made in all three hospitals, laboratory tests were requested to confirm diagnoses in which 157 (67.7\%), 48 (20.7\%) and 27 (11.6\%) were from KCMC, St Joseph and Mawenzi, respectively.

Table 1: Antibiotic prescriptions among patients with provisional diagnosis of malaria case made by different professionals

\begin{tabular}{lllll}
\hline $\begin{array}{l}\text { Professional } \\
\text { level }\end{array}$ & $\begin{array}{l}\text { KCMC } \\
\mathbf{N}(\%)\end{array}$ & $\begin{array}{l}\text { St. Joseph } \\
\mathbf{N}(\%)\end{array}$ & $\begin{array}{l}\text { Mawenzi } \\
\mathbf{N}(\%)\end{array}$ & $\begin{array}{l}\text { Total } \\
\mathbf{N}(\%)\end{array}$ \\
\hline Specialist & $4(1.6)$ & 0 & 0 & $4(1.6)$ \\
Resident* & $105(42.0)$ & 0 & 0 & $105(18.0)$ \\
Intern doctor & $47(18.8)$ & 0 & 0 & $47(18.8)$ \\
Others** & $1(0.4)$ & $58(23.2)$ & $35(14.0)$ & $94(37.6)$ \\
Total & $157(62.8)$ & $58(23.2)$ & $35(14.0)$ & $250(100)$
\end{tabular}

All Percentages in parentheses are computed as n/250X100. * Master of Medicine student. **Include Clinical officers, AMOs and Medical Assistants

Among laboratory tests requested, 89.2\% (207/232) were blood slides for microscopic detection of malaria parasites followed by malaria rapid diagnostic tests (3.01\%) and other tests $(3.01 \%)$ which included full blood picture and clinical biochemistry tests. Out of prescriptions made in each hospital, KCMC requested $92.52 \%$ (136/147) blood slide tests, $2.72 \%$ mRDTs and $4.76 \%$ of the other tests (Figure 2). St Joseph and Mawenzi Regional Hospital requested 93.47\% (43/46) and $100.00 \%$ (28/28) BS tests, respectively (Figure 2). There were no significant differences between hospitals with respect to the types and numbers of laboratory test requests made. 
Table 2: Number (\%) of antibiotic prescriptions per professional cadre in which laboratory tests were requested

\begin{tabular}{lllll}
\hline Professional level & KCMC & St. Joseph & Mawenzi & Total \\
\hline Specialist & $4(1.7)$ & 0 & 0 & $4(1.7)$ \\
Resident* & $105(45.3)$ & 0 & 0 & $105(45.3)$ \\
Intern doctor & $47(20.3)$ & 0 & 0 & $47(20.3)$ \\
Others** & $1(0.4)$ & $48(20.7)$ & $27(11.6)$ & $76(32.8)$ \\
Total & $157(67.7)$ & $48(20.7)$ & $27(11.6)$ & $232(100)$ \\
\hline
\end{tabular}

All Percentages in parentheses are computed as $\mathrm{n} / 232 \mathrm{X} 100$

Key: * = Master of Medicine students; ** = Include Clinical Officers and Assistant Medical Officer

In the majority of prescriptions across all three hospitals, treatment was initiated before laboratory results were obtained (Figure 1). Majority $(86.4 \%$; $133 / 154)$ of the prescriptions from KCMC were made before laboratory tests. Prescriptions made before laboratory results in the other hospitals were $72.4 \%$ (42/58) and 91.4\% (32/35) at St Joseph and Mawenzi, respectively. The difference between Mawenzi and the facilities was statistically significant $\left(\chi^{2}=7.787, p \leq 0.05\right)$.

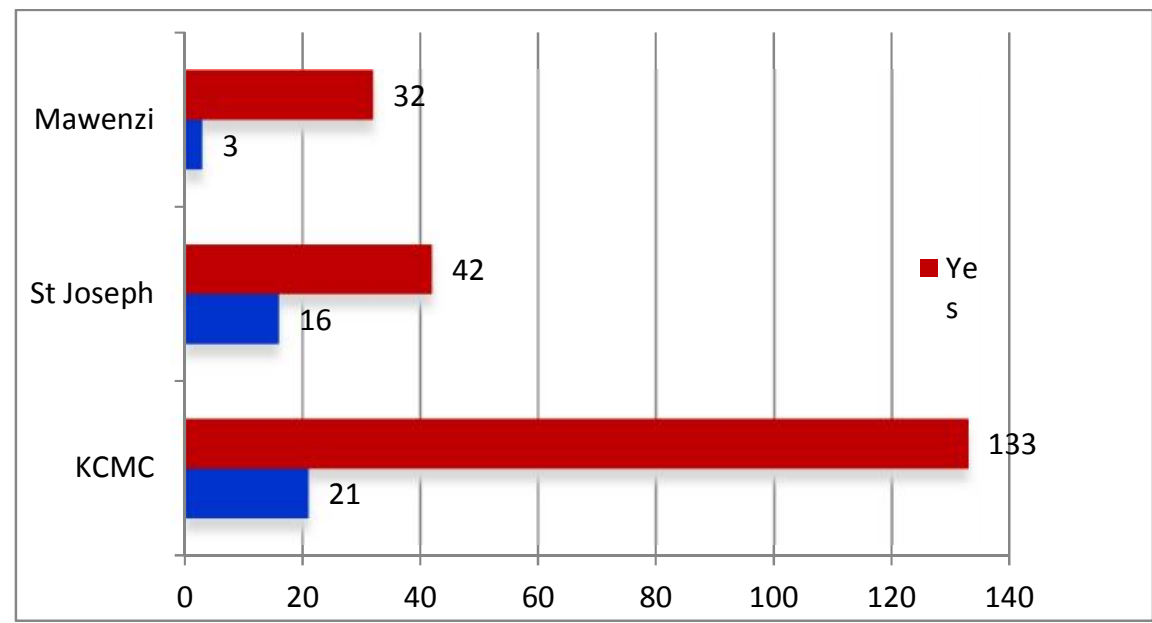

Figure 1: Number of prescriptions in which treatment was started before laboratory results

A significantly higher number of prescriptions made before laboratory findings were observed in KCMC compared to Mawenzi and St Joseph hospitals $\left(\chi^{2}=7.787, p<0.05\right)$. Of the 204 laboratory tests requested, $22(10.8 \%)$ were positive for malaria infection. St Joseph Health-Hospital and $M R H$ had a significant tendency of having negative results compared to KCMC $\left(X^{2}=19.161\right.$, $\mathrm{p}=0.001$.) (Figure 2).

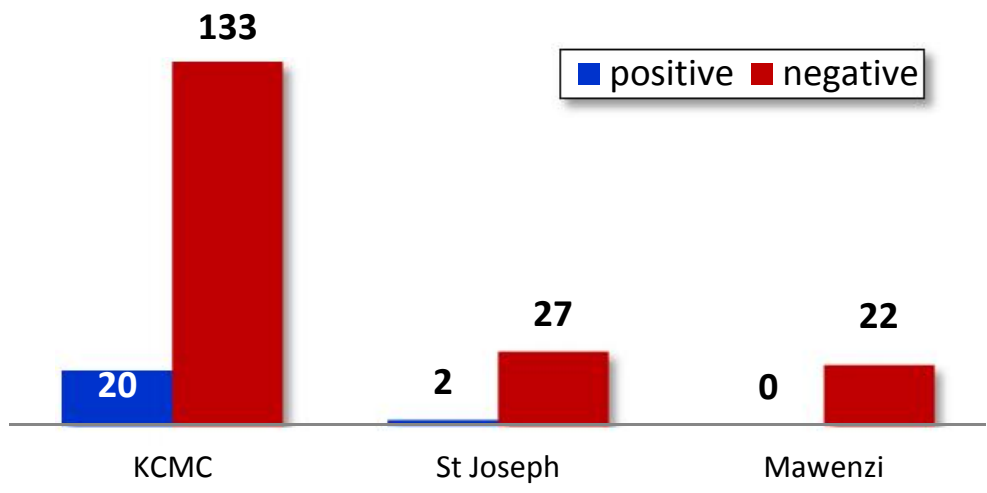

Figure 2: Results of malaria laboratory test requested 
The types and patterns of antibiotics prescriptions made were analysed. Prescriptions from KCMC were more likely to include at least one type of antibiotic and 'other drugs' compared to other Mawenzi or St. Joseph hospitals. About one third (34.0\%; 85/151) prescriptions made at KCMC contained at least one type of an antibiotic. Antibiotics prescription rates were in $42.1 \%$ (24/57) and 38.1\% (16/42) of the cases at St Joseph and Mawenzi, respectively. There was a strong association between health facility and antibiotics prescription. While KCMC prescribed antibiotics at the highest rate, Mawenzi had the lowest rates $\left(\chi^{2}=29.234, p<0.001\right)$. There was less likelihood to prescribe antibiotics at Mawenzi Regional Hospital and St Joseph Hospital by $62 \%$ and $58 \%$, respectively ( $\mathrm{p}<0.001$ and 0.021 , respectively) compared to KCMC.

Table 3: Types and patterns of prescription of antibiotics and other drugs

\begin{tabular}{lllll}
\hline Type of drug/combination & KCMC & St Joseph & Mawenzi & Total \\
\hline Antimalarial + Pain killer & 20 & 21 & 20 & 61 \\
Antimalarial + Antibiotic & 14 & 0 & 1 & 15 \\
Antimalarial + Antibiotic+Pain killer & 26 & 0 & 4 & 30 \\
Antimalarial & 5 & 6 & 3 & 14 \\
Antibiotic & 14 & 1 & 1 & 16 \\
Pain killer & 16 & 6 & 3 & 25 \\
Antibiotic +Pain killer & 15 & 3 & 2 & 20 \\
Antibiotic + other drugs* & 13 & 19 & 5 & 37 \\
Mixture of Antibiotics & 3 & 1 & 3 & 7 \\
Other drugs & 15 & 0 & 0 & 15 \\
Antimalarial+other drugs & 10 & 0 & 0 & 10 \\
Total Prescriptions per site (n1) & 151 & 57 & 42 & 250 \\
$\%(\mathrm{n} 1 / 250 * 100)$ & $60.4 \%$ & $22.8 \%$ & $16.8 \%$ & $100 \%$ \\
Prescriptions with an antibiotic $(\mathrm{n} 2)$ & 85 & 24 & 16 & 125 \\
$\%(\mathrm{n} 2 / 250 * 100)$ Across hospitals & $34 \%$ & $9.6 \%$ & $6.4 \%$ & $50 \%$ \\
$\%\left(\mathrm{n} 2 / \mathrm{n} 1 *_{100}\right)$ Within hospital & $56.29 \%$ & $42.10 \%$ & $38.09 \%$ & \\
\hline
\end{tabular}

Numbers represent the number of prescriptions

\section{Discussion}

Since misuse of antibiotics is a serious, progressive global public-health problem, we sought to understand antibiotics prescription practices of cases presumptively diagnosed with malaria in hospitals located in an urban area of northern Tanzania. Of particular interest were the extent and reasons for antibiotics prescription in cases whose treatment does not necessarily require antibiotics prescription using malaria as a model. It was found in this study that most clinicians requested laboratory tests in additional to making provisional diagnoses. Since this study focused on malaria cases, it was not surprising that most of tests requested were malaria confirmation tests. Microscopy was the leading test requested (Moody, 2002; Perandin et al., 2004; Hawkes \& Kain, 2007). However, most of the tests were found to be negative for malaria. This low malaria positivity is supported by findings of a national survey that indicate low malaria prevalence among children in the region (THMIS, 2012).

It was observed that a higher number of prescriptions were made before laboratory results were received in all the three facilities. For this particular aspect, KCMC had made most of prescriptions before laboratory results were obtained. This large number of patients at KCMC indicates a corresponding number of prescriptions and laboratory test requests made per day. Despite the continuous expansion of services at the hospital, it is by far overwhelmed by the 
number of patients that seek medical care. This mismatch between the hospital capacity and number of patients may partially explain why most malaria cases were treated before laboratory results were obtained. Further, in a previous study it has been reported that there is mistrust between clinicians and laboratory staff and the collaboration between the two is rare. This leads to clinicians' lack of respect for and confidence in laboratory professionals and the results they produce (Tuijn et al., 2014). These results from a referral medical facility in Tanzania could be a reliable representative of what is happening in many parts of the world. In part, prescription based on provisional diagnosis alone could be due to the observed mismatch between the capacity of the health care facility versus the overwhelming number of patients and dilapidated laboratory facility. Building laboratory capacity to provide accurate, rapid and affordable diagnostic results will not only provide more effective health care but also an optimal expenditure of the usually limited health care resources.

Despite the fact that the Tanzania Ministry of Health has recently authorized the use of mRDTs for diagnosis of malaria, all mRDTs requests were recorded at KCMC alone. The use of mRDT was not common in the other two hospitals. The relatively low waiting time for microscopy is also likely to have contributed to high rate of prescriptions before laboratory results were available to the clinicians. The emphasis on the use of mRDT will likely to be a means to offset the large numbers of blood smear requests that calls for the more laborious and labour intensive microscopic malaria diagnosis.

We have observed widespread use of antibiotics in malaria cases. At least an antibiotic was prescribed for over half of cases diagnosed with malaria at KCMC. Under conditions where laboratory investigations are not made available on time to confirm diagnoses, presumptive diagnosis followed by treatment, becomes the common practice. In the absence of protocol for the treatment of patients testing negative for malaria, the likelihood of febrile cases been treated with antibiotics is higher. In reality clinicians, based on presumptive diagnosis, prescribe antibiotics for cases whose diagnoses are uncertain, usually suspected to be bacterial infections (Chandler et al. 2008). We have seen that specialists at KCMC made the fewest laboratory requests before prescribing and all of which were positive. In one perspective, this may be explained by the high level of professional skills and experience specialists may have in making accurate provisional diagnosis. As many patients in sub-Saharan Africa will have both, malaria parasitaemia and bacterial illnesses (Gwer et al., 2007; Chandler et al., 2008), this approach may seem to be appropriate where there is high clinical suspicion and laboratory confirmation cannot be guaranteed.

In most instances, hospital physicians prescribe antibiotics excessively and inappropriately. The adverse consequences of misuse of antibiotics especially broad spectrum antibiotics are many and pose an urgent, progressive and worldwide public-health problem (Goossens et al., 2005). Irrational use of antibiotics is furthermore related to unnecessary exposure to adverse effects, costs and patients' re-consultation (Bartlett, 2002; Wise, 2004; Moore et al., 2009). There are various factors known to contribute to the occurrence of resistance including misuse of antibiotics, patient and clinician factors, the use of monotherapy, veterinary prescriptions and over the counter sale of antibiotics (Struelens, 1998). Doctor's prescribing behaviour is one of the factors determining inappropriate use of antibiotics (Quet et al., 2015).

Many factors have also been described to influence antibiotics prescription habits. According to Teixeira Rodrigues et al., (2012) antibiotic prescribing is a complex process influenced by factors affecting all the actors involved, including healthcare providers, healthcare system, patients and the general public. Clinicians may prescribe antibiotics just to be on the safe side especially when there is diagnostic uncertainty and lack of prescriber's knowledge regarding optimal diagnostic approaches or lack of opportunity for patient follow up. In this case, the clinician treats patients against failure for fear of their competence being undermined. A study in Cameroon has reported that, doctors made malaria diagnosis anyway despite the absence of 
laboratory confirmation with the notion that 'the doctor treats the body and the soul' (Chandler et al., 2012). This implies that even in the absence of malaria parasites, patients would be psychologically treated by being given medications including antibiotics. Insufficient training in infectious diseases and antibiotic treatment, patient pressure for medications (Chandler et al., 2012), difficulty of selecting the appropriate anti-infective drugs empirically and the need for selfre-assurance are all factors known to promote the unnecessary use of broad spectrum antibiotics (Struelens, 1998). In some studies patient pressure has been described as a factor in influencing antibiotic prescribing (Scott et al., 2001; Rowbotham \& Peters, 2013; Thriemer et al., 2013). However, this could not be established in our current study.

In conclusion, although our study was limited by the small number of health facilities and files reviewed, and absence of interviews with clinicians and patients, we report a high rate of antibiotic treatment based on provisional diagnoses in hospitals in northern Tanzania. This high rate of antibiotic prescription is likely to favour development and spread of resistance of bacterial pathogens to common antibiotics. It is important that interventions to educate clinicians about the dangers of irrational use of antibiotics including drug resistance are emphasized.

\section{Competing Interests}

The authors declare that they have no competing interest

\section{Authors' contributions}

JC designed the study, reviewed files and wrote the manuscript. EM, DK, HS, EK participated in data collection. EK participated in data collection, provided critical advice on data analysis and manuscript writing. BN critically reviewed the manuscript, AJ conducted data analyses. All authors read and approved the final version of the manuscript.

\section{Acknowledgements}

This study was conducted with financial support from the MRTP under the HRSA (US National Institutes of Health) funded KCMC-MEPI grant \#T84HA21123-02 and The Kilimanjaro Christian Medical University College. This support is highly acknowledged.

\section{References}

Awad, A. I., Ball, D. E. \& Eltayeb, I. B. (2007) Improving rational drug use in Africa: the example of Sudan. Eastern Mediterranean Health Journal 13, 1202-1211.

Bartlett, J.G. (2002) Antibiotic-associated diarrhea. New England Journal of Medicine 346, 334-339.

Bharathiraja, R., Sridharan, S., Chelliah, L. R., Suresh, S. \& Senguttuvan, M. (2005). Factors affecting antibiotic prescribing pattern in pediatric practice. The Indian Journal of Pediatrics 72, 877-879.

Biswas, N.R., Biswas, R.S., Pal, P.S., Jain, S.K., Malhotra, S.P., Gupta, A.S.H.O. \& Pal, S.N. (2000) Patterns of prescriptions and drug use in two tertiary hospitals in Delhi. Indian Journal of Physiology and Pharmacology 44, 109-112.

Buke, C., Hosgor-Limoncu, M., Ermertcan, S., Ciceklioglu, M., Tuncel, M., Köse, T. \& Eren, S. (2005). Irrational use of antibiotics among university students. Journal of Infection 51, 135139.

Calva, J. (1996) Antibiotic use in a periurban community in Mexico: a household and drugstore survey. Social Science \& Medicine 42, 1121-1128.

Chandler, C. I., Mangham, L., Njei, A. N., Achonduh, O., Mbacham, W. F. \& Wiseman, V. (2012) 'As a clinician, you are not managing lab results, you are managing the patient': how the 
enactment of malaria at health facilities in Cameroon compares with new WHO guidelines for the use of malaria tests. Social Science \& Medicine 74, 1528-1535.

Chandler, C., Jones, C., Boniface, G., Juma, K., Reyburn, H. \& Whitty, C. (2008) Guidelines and mindlines: why do clinical staff over-diagnose malaria in Tanzania? A qualitative study. Malaria Journal 7:53.

Davey, P., Brown, E., Charani, E., Fenelon, L., Gould, I.M., Holmes, A., Ramsay, C.R., Wiffen, P.J. \& Wilcox, M. (2013) Interventions to improve antibiotic prescribing practices for hospital inpatiens. Cochrane Database of Systematic Reviews 2013, Issue 4. Art. No. CD003543.

Fabricant, S.J. \& Hirschhorn, N. (1987) Deranged distribution, perverse prescription, unprotected use: the irrationality of pharmaceuticals in the developing world. Health Policy and Planning 2, 204-213.

Gilson, L., Jaffar, S., Mwankusye, S. \& Teuscher, T. (1993) Assessing prescribing practice: a Tanzanian example. The International Journal of Health Planning and Management 8, 37-58.

Goossens, H., Ferech, M., Vander Stichele, R. \& Elseviers, M. (2005) Outpatient antibiotic use in Europe and association with resistance: a cross-national database study. The Lancet 365, 579-587.

Gwer, S., Newton, C. R. \& Berkley, J. A. (2007) Over-diagnosis and co-morbidity of severe malaria in African children: a guide for clinicians. The American Journal of Tropical Medicine and Hygiene 77, 6-13.

Hawkes, M. \& Kain, K.C. (2007) Advances in malaria diagnosis. Expert Review of Anti-Infective Therapy 5, 485-95.

Ishengoma, D.R.S., Rwegoshora, R.T., Mdira, K.Y., Kamugisha, M.L., Anga, E.O., Bygbjerg, I.C., Rønn, A.M. \& Magesa, S.M. (2013) Health laboratories in the Tanga region of Tanzania: the quality of diagnostic services for malaria and other communicable diseases. Annals of Tropical Medicine \& Parasitology 103, 441-453.

Karande, S., Sankhe, P. \& Kulkarni, M. (2005) Patterns of prescription and drug dispensing. The Indian Journal of Pediatrics, 72, 117-121.

Kardas, P., Devine, S., Golembesky, A. \& Roberts, C. (2005) A systematic review and metaanalysis of misuse of antibiotic therapies in the community. International Journal of Antimicrobial Agents 26, 106-113.

Kumar, R., Indira, K., Rizvi, A., Rizvi, T. \& Jeyaseelan, L. (2008) Antibiotic prescribing practices in primary and secondary health care facilities in Uttar Pradesh, India. Journal of Clinical Pharmacy and Therapeutics 33, 625-634.

Massambu, C. \& Mwangi, C. (2009) The Tanzania Experience Clinical Laboratory Testing Harmonization and Equipment Standardization at Different Levels of a Tiered Health Laboratory System. American Journal of Clinical Pathology 131, 861-866.

Mnyika, K.S. \& Killewo, J.Z.J. (1991) Irrational drug use in Tanzania. Health Policy and Planning 6, 180-184.

Moody, A. (2002) Rapid diagnostic tests for malaria parasites. Clinical Microbiology Reviews 15, 66-78.

Moore, M., Little, P., Rumsby, K., Kelly, J., Watson, L., Warner, G., Fahey, T. \& Williamson, I. (2009) Effect of antibiotic prescribing strategies and an information leaflet on longerterm reconsultation for acute lower respiratory tract infection. British Journal of General Practice 59, 728-734.

Mshana, S.E., Matee, M. \& Rweyemamu, M. (2013) Antimicrobial resistance in human and animal pathogens in Zambia, Democratic Republic of Congo, Mozambique and Tanzania: an urgent need for a sustainable surveillance system. Annals of Clinical Microbiology \& Antimicrobials 12: 28.

Ngasala, B., Mubi, M., Warsame, M., Petzold, M.G., Massele, A.Y., Gustafsson, L.L., Tomson, G., Premji, Z. \& Bjorkman, A. (2008) Impact of training in clinical and microscopy diagnosis of 
childhood malaria on antimalarial drug prescription and health outcome at primary health care level in Tanzania: a randomized controlled trial. Malaria Journal 7, 199.

Nsimba, S.E. (2006) Assessing prescribing and patient care indicators for children under five years old with malaria and other disease conditions in public primary health care facilities. Southeast Asian Journal of Tropical Medicine and Public Health 37, 206-214.

Okeke, I.N., Lamikanra, A. \& Edelman, R. (1999) Socioeconomic and behavioral factors leading to acquired bacterial resistance to antibiotics in developing countries. Emerging Infectious Diseases 5, 18.

Pechere, J.C. (2001) Patients' interviews and misuse of antibiotics. Clinical Infectious Diseases 33, S170-S173.

Perandin, F., Manca, N., Calderaro, A., Piccolo, G., Galati, L., Ricci, L., Medici, M. C., Arcangeletti, M. C., Snounou, G. \& Dettori, G. (2004) Development of a real-time PCR assay for detection of Plasmodium falciparum, Plasmodium vivax, and Plasmodium ovale for routine clinical diagnosis. Journal of Clinical Microbiology 42, 1214-1219.

Petti, C.A., Polage, C.R., Quinn, T.C., Ronald, A.R. \& Sande, M.A. (2006) Laboratory medicine in Africa: a barrier to effective health care. Clinical Infectious Diseases 42, 377-382.

Phillips, I., Casewell, M., Cox, T., De Groot, B., Friis, C., Jones, R., Nightingale, C., Preston, R. \& Waddell, J. (2004) Does the use of antibiotics in food animals pose a risk to human health? A critical review of published data. Journal of Antimicrobial Chemotherapy 53, 2852.

Prescott, J.F. \& Baggot, J.D. (1993) Antimicrobial Therapy in Veterinary Medicine. lowa State University Press.

Reyburn, H., Mbakilwa, H., Mwangi, R., Mwerinde, O., Olomi, R., Drakeley, C. \& Whitty, C. J. (2007) Rapid diagnostic tests compared with malaria microscopy for guiding outpatient treatment of febrile illness in Tanzania: randomised trial. BMJ 334, 403.

Rowbotham, S. \& Peters, S. (2013) Resisting patient demands for antibiotics. Nursing Times 109, 14-15.

Scott, J.G., Cohen, D., DiCicco-Bloom, B., Orzano, A.J., Jaen, C.R. \& Crabtree, B.F. (2001) Antibiotic use in acute respiratory infections and the ways patients pressure physicians for a prescription. Journal of Family Practice 50, 853-858.

Sharma, M., Eriksson, B., Marrone, G., Dhaneria, S. \& Lundborg, C.S. (2012) Antibiotic prescribing in two private sector hospitals; one teaching and one non-teaching: a cross-sectional study in Ujjain, India. BMC Infectious Diseases 12: 155.

Siddiqi, S., Hamid, S., Rafique, G., Chaudhry, S.A., Ali, N., Shahab, S. \& Sauerborn, R. (2002) Prescription practices of public and private health care providers in Attock District of Pakistan. The International Journal of Health Planning and Management 17, 23-40.

Singer, R.S., Finch, R., Wegener, H.C., Bywater, R., Walters, J. \& Lipsitch, M. (2003) Antibiotic resistance-the interplay between antibiotic use in animals and human beings. The Lancet Infectious Diseases 3, 47-51.

Straand, J., Rokstad, K.S. \& Sandvik, H. (1998) Prescribing systemic antibiotics in general practice: A report from the $M$ re \& Romsdal Prescription Study. Scandinavian Journal of Primary Health Care 16, 121-127.

Struelens, M.J. (1998) The epidemiology of antimicrobial resistance in hospital acquired infections: problems and possible solutions. BMJ 317, 652-654.

Teixeira Rodrigues, A., Roque, F., Falcão, A., Figueiras, A. \& Herdeiro, M.T. (2012) Understanding physician antibiotic prescribing behaviour: a systematic review of qualitative studies. International Journal of Antimicrobial Agents 41, 203-212.

Thriemer, K., Katuala, Y., Batoko, B., Alworonga, J.P., Devilieger, H., Van Geet, C. (2013) Antibiotic prescribing in DR Congo: a knowledge, attitude and practice survey among medical doctors and students. PLoS One 3:8 (2):e55495. 
Tuijn, C. J., Msoka, E., Mushi, D. L., Sumari-de Boer, M., Chilongola, J. \& Van den Broek, A. (2014) The interface between clinicians and laboratory staff: a field study in northern Tanzania: original research. African Journal of Laboratory Medicine 3, 1-7.

Turnidge, J. (2004) Antibiotic use in animals: prejudices, perceptions and realities. Journal of Antimicrobial Chemotherapy 53, 26-27.

van den Bogaard, A.E. \& Stobberingh, E.E. (2000) Epidemiology of resistance to antibiotics: links between animals and humans. International Journal of Antimicrobial Agents 14, 327-335.

Van den Broek, A., Tuijn, C. J., Van't Klooster, L., Msoka, E., Sumari-de Boer, M., Chilongola, J. \& Oskam, L. (2014) Understanding the interface between clinical and laboratory staff: original research. African Journal of Laboratory Medicine 3, 1-6.

Wise, R. (2004) The relentless rise of resistance? Journal of Antimicrobial Chemotherapy 54, 306310.

Zarb, P., Amadeo, B., Muller, A., Drapier, N., Vankerckhoven, V., Davey, P., Goossens H; ESAC-3 Hospital Care Subproject Group (2011) identification of targets for quality improvement in antimicrobial prescribing: the web-based ESAC Point Prevalence Survey, 2009. Journal of Antimicrobial Chemotherapy 66, 443-449. 